\title{
A Practical Framework for River-Quality Assessment
}

River-Quality Assessment of the Willamette River Basin, Oregon

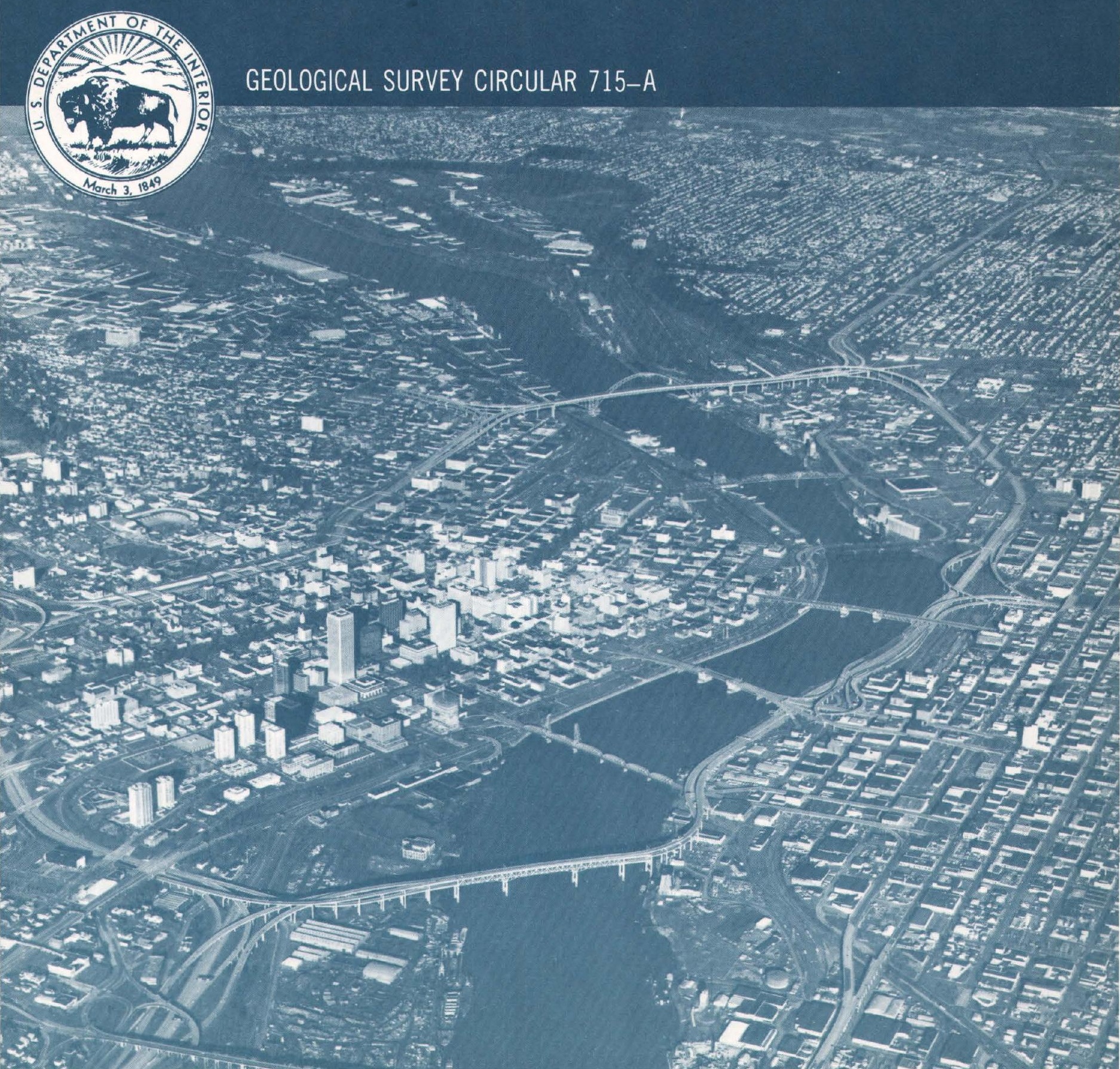





\section{A Practical Framework for River-Quality Assessment}

By David A. Rickert and Walter G. Hines

RIVER-QUALITY ASSESSMENT OF THE WILLAMETTE RIVER BASIN, OREGON

GEOLOGICAL SURVEY CIRCULAR 7I5-A 


\section{United States Department of the Interior}

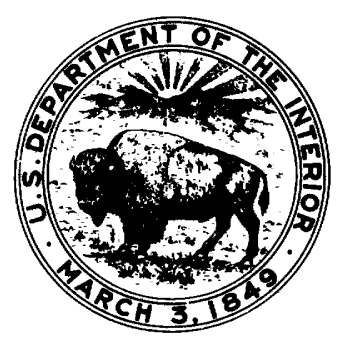

\section{Geological Survey V. E. McKelvey, Director}

First printing 1975

Second printing 1980

Library of Congress Cataloging in Publication Data

Rickert, David A. $1940-$

A practical framework for river-quality assessment. (River-quality assessment of the Willamette River Basin, Oregon)

(Geological Survey Circular 715-A)

Bibliography: p. A16-A17.

Supt. of Docs. No.: I 19.4/2:715-A

1. Water quality management. I. Hines, Walter G., joint author. II. Title. III. Series. IV. Series: United States Geological Survey Circular 715-A.

$\begin{array}{llr}\text { QE75.C5 no. 715-A [TD365] 557.3'08s [333.9'162] } & \text { 75-619203 }\end{array}$ 


\section{FOREWORD}

The American public has identified the enhancement and protection of river quality as an important national goal, and recent laws have given this commitment considerable force. As a consequence, a considerable investment has been made in the past few years to improve the quality of the Nation's rivers. Further improvements will require substantial expenditures and the consumption of large amounts of energy. For these reasons, it is important that alternative plans for river-quality management be scientifically assessed in terms of their relative ability to produce environmental benefits. To aid this endeavor, this circular series presents a case history of an intensive river-quality assessment in the Willamette River basin, Oregon.

The series examines approaches to and results of critical aspects of riverquality assessment. The first several circulars describe approaches for providing technically sound, timely information for river-basin planning and management. Specific topics include practical approaches to mathematical modeling, analysis of river hydrology, analysis of earth resources-river quality relations, and development of data-collection programs for assessing specific problems. The later circulars describe the application of approaches to existing or potential river-quality problems in the Willamette River basin. Specific topics include maintenance of high-level dissolved oxygen in the river, effects of reservoir release patterns on downstream river quality, algal growth potential, distribution of toxic metals, and the significance of erosion potential to proposed future land and water uses.

Each circular is the product of a study devoted to developing resource information for general use. The circulars are written to be informative and useful to informed laymen, resource planners, and resource scientists. This design stems from the recognition that the ultimate success of river-quality assessment depends on the clarity and utility of approaches and results as well as their basic scientific validity.

Individual circulars will be published in an alphabetical sequence in the Geological Survey Circular 715 series entitled "River-Quality Assessement of the Willamette River Basin, Oregon."

J.S. Cragwall, Jr.

Chief Hydrologist 
Cover: Willomette River as it winds through Portland, Oregon. Photograph taken by Hugh Ackroyd. 


\section{CONTENTS}

Foreword -

Abstract _...

Introduction

River-quality assessment

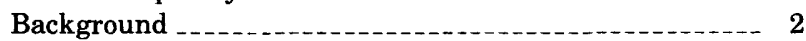

Interrelation of river-quality assessment and river-basin planning -.............. 3

Communication: A key factor in interdisciplinary assessment and planning

Elements of river-quality assessment

Overview

Delineation of river-quality problems
Elements of river-quality assessment - Continued

Analysis of river hydrology

Selection of assessment methods _.............. 7

Identification, collection, and collation of required data -

Data analysis, method formulation, and the testing of

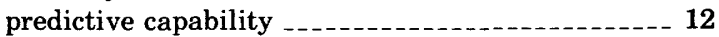

Forecasting impacts of planning alternatives _.... 12

Communication of results _.......... 13

Program evaluation ....... 16

Summary and discussion

References cited

FIGURE 1. Schematic showing the interrelation of river-quality assessment and river-basin planning.

2. Diagram representing the Willamette River, Oreg., showing distinctive hydrologic reaches and elevation profile 8

3. Diagram showing relative difficulty of applied modeling

4. Schematic showing the interrelation of data analysis, method formulation, and the testing of predictive capability 13

5. Graph showing relation between dissolved oxygen and summer-condition discharge for Willamette River, Oreg., at river mile 6

6. Schematic showing the process of assessing the impacts of land-use activity on erosion and river quality ---- 15

\section{TABLE}

TABLE 1. Selected physical characteristics of the main stem Willamette River

\section{CONVERSION FACTORS}

Multiply English units

Feet (ft)

Miles (mi)

Cubic feet per second $\left(\mathrm{ft}^{3} / \mathrm{s}\right)$

Feet per mile $(\mathrm{ft} / \mathrm{mi})$

$$
\text { By }
$$
0.3048 1.609 28.32
To obtain SI units Metres (m) Kilometres (km) Litres per second $(1 / \mathrm{s})$ Cubic metres per second $\left(\mathrm{m}^{3} / \mathrm{s}\right)$ Metres per kilometre $(\mathrm{m} / \mathbf{k m})$ 



\title{
A PRACTICAL FRAMEWORK FOR RIVER-QUALITY ASSESSMENT
}

\author{
By David A. Rickert and Walter G. Hines
}

\section{ABSTRACT}

The U.S. Geological Survey is now (1975) conducting an intensive river-quality assessment of the Willamette River basin, Oregon. The objectives are (1) to define a practical framework for conducting comprehensive river-quality assessments; (2) to determine the kinds and amounts of data required to adequately assess various types of river-quality problems; (3) to develop and document methods for evaluating basin-development alternatives in terms of potential impacts on river quality; and (4) to apply the framework, data, and methods to assess the existing or potential river-quality problems of the Willamette River basin.

This paper describes the results of the first objective. The defined framework involves a seven-step iterative process which includes: (1) determination, in conjunction with resource planners and managers, of existing and potential river-quality problems; (2) analysis of river hydrology; (3) selection and development of applicable assessment methods; (4) identification, collection, and collation of required data; (5) analysis of data and formulation of assessment methods to provide predictive capability; (6) forecasting the impacts of planning alternatives on each problem; and (7) effective communication of results to the planning and management community, including the general public.

The seven steps provide a rational framework for organizing and executing technically sound assessments of river-quality problems and planning alternatives. All steps and ideas are tempered by a goal of providing technically sound, adequate, and timely information for decisionmaking. The framework stresses communication and is designed to be a joint venture, from beginning to end, including scientists, planners, and resource managers. The design stems from the recognition that the ultimate success of each assessment depends on the clarity and utility of results as well as on their basic scientific validity.

\section{INTRODUCTION}

Today there is an urgent need for comprehensive resource assessment in most river basins of the United States. In response to this need, many planning groups have prepared reports that project future demands for water supply, waste-water treatment, and other services, and suggest possible alternatives for meeting the demands. Implicit in these reports is the acceptance of economic and population growth, but in a manner consistent with some desired level of land and river quality.

A planning report is not an end in itself, but merely a step in the resource-management process. The actual decisions are usually made by elected or appointed officials with assistance from resource scientists and planners.

Virtually all forms of growth and development exert some impact on river quality. Achievement of desirable river quality at acceptable cost requires that management decisions be based on sound impact assessments, not on arbitrary assumptions. Thus, the vital link between resourcedevelopment plans and management decisions is scientific assessment to predict the probable impacts of each planning alternative. At present, river-quality assessment is the Achilles' heel of the overall process. The difficulty in appraising impacts results from (1) the absence of a rational framework for structuring such work, (2) the lack, poor development, and misapplication of assessment methods, and (3) the scarcity of reliable data.

To bridge the gap between planning and decisionmaking, this paper presents a practical framework for conducting river-quality assessments. Subsequent papers will focus on the design of data programs and the application of methods for assessing specific river-quality problems.

\section{RIVER-QUALITY ASSESSMENT}

River quality is the physical, chemical, and biological character of a river with regard to its suitability for a specified purpose. A river may be of good quality for one purpose, and bad for another, depending on its characteristics and the criteria by which quality is judged.

The characteristics and criteria for judging 
quality are based on scientific knowledge and popular perceptions. Popular perceptions, in turn, depend primarily on environmental, economic, and demographic conditions. As these conditions change, perceived purposes and suitabilities of rivers change, and the resource decisionmaker is often left without adequate scientific information to evaluate alternatives.

The concept of river-quality assessment was developed to fill this information vacuum. The goal of river-quality assessment is to provide sound technical information that is appropriate and adequate for resource decisionmaking. The approach is to define the major environmental and cultural controls of those characteristics of a river that decisionmakers perceive as being most important to resource planning and management. These characteristics can be (1) existing conditions widely perceived as problems or (2) parameters sensitive to growth and development which must be managed to maintain "desirable quality." In the context of planning, both represent river-quality problems.

To enable decisionmakers to evaluate alternatives, river-quality assessments must provide information on the potential impacts of land and water development. Provision of such information requires that important problems are analyzed in terms of cause and effect. Other analytical approaches have been used to study river quality (for example, trends and indices), but only an approach based on definition of cause-effect relationships can provide an ability to predict impacts of planning alternatives.

\section{BACKGROUND}

Historically, many Federal agencies collected water-quality data, resulting in duplication of effort and significant differences in data standards. In 1964, in an attempt to correct these problems, the Bureau of the Budget (Executive Office of the President, 1964) issued Circular A-67 designating the Department of the Interior as the lead agency in coordinating Federal activities in water-data acquisition. Responsibility for execution of the functions was assigned by the Department specifically to the U.S. Geological Survey.

Circular A-67 prescribed creation of Federal and non-Federal committees to assist the Geological Survey in coordinating designated functions. The non-Federal committee was officially named the Non-Federal Committee on Water Data for Public Use. This committee was created recognizing that the non-Federal sector both uses and acquires a major part of the Nation's water data. The committee includes 26 representatives of wateroriented organizations: among these are national, State, and regional organizations, professional and technical societies, and the academic community. The major function of the committee is to advise the Geological Survey on existing, future, and emergency needs for water-resource data.

Several years ago, the Non-Federal Committee voiced concern at the lack of suitable information for adequate river-basin planning. The concern resulted from the lack of reliable data to address problems that, because of public consciousness and pending legislation, demanded immediate assessment. These problems included (1) definition of the existing quality of the Nation's rivers; (2) analysis of quality trends, especially as to whether pollution-control programs were actually improving river quality; (3) determination of whether advanced waste treatment was desirable or necessary on a national, State, or river-basin scale; (4) definition of the interrelations of land use and river quality; and (5) assessment of reservoir operation and flow regulation on river quality.

In 1971, Wolman (1971) reviewed these and related problems in the context of data-collection programs. He concluded that designs of past and existing water-data programs were unsuited to provide information for assessing these problems or for defining meaningful measures of river quality. Wolman further noted, as had the Advisory Committee, that little interpretive use was being made of the data that did exist.

In 1971, the Non-Federal Advisory Committee formally recommended that the Geological Survey conduct an interdisciplinary river-quality study. The recommended objectives were (1) to define a practical framework for conducting comprehensive river-quality assessments; (2) to determine the kinds and amounts of data required to adequately assess various types of river-quality problems; (3) to develop and document methods for assessing planning alternatives in terms of potential impacts on river quality; and (4) to apply the framework, data, and methods to assess the critical river-quality problems of a major river basin.

The Geological Survey responded to the Committee's recommendation by starting in January 


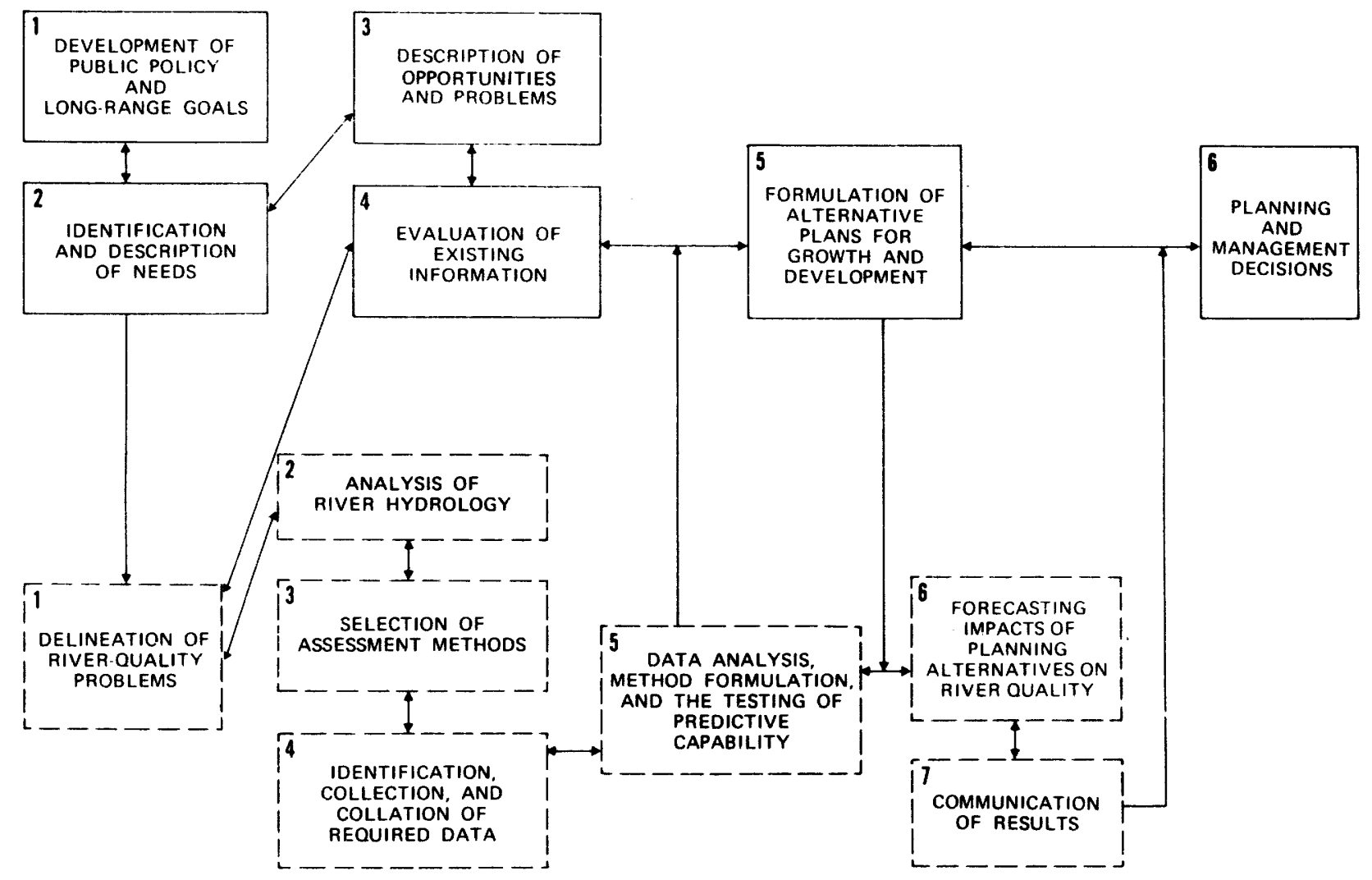

Figure 1.--Interrelation of river-quality assessment and river-basin planning.

1973 a prototype river-quality assessment study in the Willamette River basin, Oregon. The Willamette River basin was selected for several reasons. First, there is an excellent base of background data, particular!y on hydrology. Second, the social and political attitudes in Oregon reflect a keen interest in environmental quality. This suggested that the people and agencies would welcome the study and that results would be used at the State and local levels. Third, a river-basin management plan already existed, as did several studies of land-use projections (Willamette Basin Task Force, 1969). Thus, the study could evaluate existing planning alternatives to provide a realistic test of assessment approaches. Fourth, the Willamette is the largest river in the Nation on which all major point-source discharges presently receive secondary waste-water treatment (Oregon Department of Environmental Quality, 1970). The quality now is above the stringent State standards, and the river is considered a national success story (Gleeson, 1972). Thus, the study could include appraisal of the factors to which past im- provement is attributed, in addition to evaluating the factors that must be managed to maintain or improve the quality.

\section{INTERRELATION OF RIVER-QUALITY ASSESSMENT AND RIVER-BASIN PLANNING}

Figure 1 illustrates an idealized integration of river-quality assessment into river-basin planning. The planning components (across the top) are outlined by solid lines to symbolize a more or less standard process, whereas the assessment components are portrayed in dashed lines to represent an undeveloped potential.

River-basin planning usually begins with the development of public policies and long-range goals (step 1). In this rase, the process normally continues with identification and description of resource needs (step 2), followed by description of opportunities and problems (step 3), and evaluation of existing information (step 4). In some basins, the process begins with step 2 , and long-range policies are eventually generated by feedback from 
steps 2, 3, and 4. Regardless of the actual order of the first four steps, step 5 is formulation of alternative plans for river-basin development (planning alternatives). Customarily, basin plans are considered complete at this point, and decisionmakers then choose among alternatives without knowledge of their probable impacts on river quality.

Ideally, river-quality assessment should be built into the planning process in a step-by-step progression. The assessment approach of the Willamette River Quality Study includes seven steps (fig. 1), beginning with delineation of existing and potential river-quality problems (step 1). The approach continues with analysis of river hydrology (step 2), which is followed by selection of suitable assessment methods (step 3). These two steps lead to and form a feedback circuit with step 4, which is identification, collection, and collation of required data. The fifth step is analysis of data and formulation of assessment methods to provide predictive capability. Step 6 focuses on using the predictive tool to forecast the impacts of planning alternatives on delineated (step 1) river-quality problems. Most alternatives derive from existing river-basin plans (step 5, River-basin planning), but viable alternatives are added that existing plans fail to consider. Finally, assessment results are communicated in concise, nontechnical formats to decisionmakers, the public, and the scientific community (step 7).

For maximum efficiency, the six steps of planning (fig. 1) and the seven steps of assessment could ultimately be integrated into one iterative network. Thus, following a period of initial organization, information would flow freely between each of the 13 steps. For simplicity of presentation, feedback loops are omitted in figure 1 , and only the major points of integration are noted between the planning and assessment processes.

To place figure 1 in perspective, it must be noted that river quality is one of many factors that decisionmakers consider in choosing among alternative plans. River quality is a single component of the natural-resource system, which, in turn, is only one aspect of the socioeconomic-politicalenvironmental structure of river-basin management. In many basins, demographic and economic uncertainties (for example, population growth, industrial development, interest rates, costs) may be greater than river-quality uncertainties. However, such a situation increases the need for assessment, because a sound understanding of river quality provides a starting point for systematic evaluation of socioeconomic and political options.

\section{COMMUNICATION: A KEY FACTOR IN INTERDISCIPLINARY ASSESSMENT AND PLANNING}

Useful assessment of complex river-quality problems requires development of a mutual understanding between the resource scientist and planner. The scientist needs to assess critical problems in the context of a planner's requirements, and the planner needs to appreciate the meaning and implication of the scientist's results. Each must appreciate how the other thinks and this requires free and continuing communication.

Unfortunately, effective communication is presently an exception rather than the rule. Most environmental assessments tend to be unilateral efforts by resource scientists. Efforts at cooperative ventures are mostly perfunctory. Attempts at communication are usually relegated to a few meetings to set up a study and a concluding meeting at which the scientist dumps voluminous, jargon-ridden reports into the laps of bewildered planners.

Mutual understanding between resource scientists and planners is most easily attained by conducting resource assessments as joint ventures from beginning to end. The effective approach begins with joint delineation of public policies, longrange goals, and appraisal of problems; continues with exploration of study methods; proceeds with joint evaluation of planning assumptions and an examination of alternatives to be tested; and ends with an iterative process of evaluation, discussion, and use of results.

As noted, the goal is to evolve beyond the mere communication of ideas to a state of mutual understanding and trust. This goal requires growth on both sides. The scientist must understand the planner's information needs, his legal, monetary, and time constraints, and the level of his ability to comprehend scientific information. The planner must understand that present scientific knowledge often limits the scientist's ability to deliver quantitative resource assessments and that each assessment method has inherent strengths and weaknesses. Both need to realize that valid data and sound analyses, rather than complex analytical methods, are the foundation of reliable resource assessment. 


\section{ELEMENTS OF \\ RIVER-QUALITY ASSESSMENT}

An understanding of the planner's needs is essential for the resource scientist to achieve efficient formulation of assessments and effective communication of results. However, the ultimate success of resource assessments is still basically dependent on the scientist's ability to produce practical and technically sound information.

The task of developing practical, scientifically valid assessments can be viewed as a stepwise cyclic process, which, if structured around flexible criteria, can yield increasingly useful information. The steps of the process are basically the same as those outlined for river-quality assessment (fig. 1), with the addition of steps to include preplanning (overview) and postevaluation criteria. These additional steps serve to create the cyclic nature that, hopefully, can ensure that each successive study can build and improve upon the last.

\section{OVERVIEW}

The foremost considerations for river-quality assessment are:

1. Results must be scientifically valid and limitations on use need to be carefully explained.

2. Results must be practical.

3. Results must be available by the time important planning decisions need to be made.

The first overview consideration will be discussed under the topic of methods. It should be noted at this point, however, that comprehensive assessments often require use of several methods and that each method has inherent limitations for projecting potential impacts of development alternatives. Some assessments will be quantitative, others qualitative. (Functional definitions of qualitative and quantitative are presented in "Selection of Assessment Methods.") All can be helpful to the planner provided the limitations of use are carefully explained.

The utility of assessments depends on the practicality of results. Understanding the planner's needs will greatly aid the scientist in formating practical approaches to produce practical results. Scientists should understand a variety of assessment methods from which they can choose the most appropriate for specific situations. For example, mathematical modeling is often best for assessing certain river-quality problems. However, with improper application, or without a strong data base, models can easily produce less practical results than those possible from less glamorous methods.

Assessments need to be accomplished within the time frame of planning needs because results are virtually useless if major decisions have already been made. The ideal is to begin studies far enough in advance of the decision timetable to provide opportunity for in-depth assessment. Where this is impossible, there are two options: (1) conduct short, preliminary studies to shed some light on the situation and then carefully explain the predictive limitations, or (2) insist on the time needed to develop adequate information. The choice will be made by the decisionmaker and dictated by the importance of the pending decision, socioeconomic and political pressures, and how badly the information is needed to adequately evaluate alternatives.

The duration of study is a compromise between taking enough time to do an appropriate level of scientific assessment and so much time that results become irrelevant to the decisionmaking process. From experience in the Willamette River basin, it appears that $2 \frac{1}{2}$ to 3 years may be a reasonable period for assessment of immediate problems. The beginning of a study needs to be timed to provide a reasonable period for planning prior to initiation of fieldwork. A $2 \frac{1}{2}$ - to 3-year study time permits 2 years of fieldwork and hence the opportunity to recheck critical time periods (of annual cycles) for specific problems. Longer studies begin to lose their usefulness to the planning process. Specific critical problems may be studied over longer periods, but the bulk of the initial assessments should be completed. Reappraisals can then be made under reduced time pressures, while full-scale updates can be scheduled on a periodic basis.

\section{DELINEATION OF RIVER-QUALITY PROBLEMS}

Delineation of problems is the first technical step of river-quality assessment. Adequate delineation requires exhaustive review of reports and interviews with knowledgeable individuals until all significant aspects have been evaluated. The success of assessment depends on how well the relevant problems are initially defined in relation to development plans and other important socioeconomic, political, and environmental factors. 
Although the delineation of problems is done in coordination with basin planners, the scientist needs to remain sensitive to the potential for problems that planners are not aware of and which previous studies did not appraise. To date, most planning studies have focused on the classical inriver parameters of dissolved oxygen, (DO), temperature, and indicator bacteria. Fewer assessments have been made of the factors which control algal growth in rivers of the distribution and effects of hazardous materials. Even less work has been done on delineating the relationships of land-use activities and erosion to subsequent river quality. Today, however, there is awakening recognition that planning for maintenance or improvement of river quality needs to be based on comprehensive, integrated assessment of land and water resources. Land-use activity controls not only the amount of wastes which reach rivers from municipal and industrial outfalls, but also the kinds and amounts of wastes which enter directly in storm runoff. In places, the materials in storm runoff may cause undesirable algal growth, metal and pesticide toxicity, and sediment problems. The situation is now such that either land use and storm runoff are considered, or else the ultimate result will be land-imposed constraints on river quality (Howells, 1971).

Once the full range of river-quality problems is delineated, the scientist and planner can collaborate in developing problem priorities. These priorities, together with planning decision deadlines, provide the basis for deciding which problems need immediate attention and which can be studied over longer periods of time.

\section{ANALYSIS OF RIVER HYDROLOGY}

River hydrology exercises a dominant control over river quality. Hydrologic characteristics determine the physical dynamics of rivers, which, in turn, control the pattern and extent of chemical and biological processes. Because of this control, analysis of river hydrology is a prerequisite to selecting a method or identifying the data needed to assess a river-quality problem. Only through such analysis can we determine the inherent (background) variability in river quality that results from natural variations in hydrology. Once this is known, the impacts of man on the basin can be examined independently of natural variations.

River hydrology is a complex interrelation of climate, geology, topography, vegetation, and man's activities such as land and water use. As described by Brown and Jackson (1973, 1975), these basic basin features also control certain land processes that directly affect river quality.

Pollution problems arising from discharge of municipal and industrial effluents are a major consideration of river-quality planning. Study of such problems focuses largely on the quantification of in-river processes, and hence, on the hydrologic factors of flow, water temperature, and channel morphology.

Flow characteristics, along with water temperatures, govern many physical, chemical, and biological river processes. In conjunction with channel morphology and temperature, flow determines the reaches where specific water-quality problems are most likely to occur. Furthermore, seasonal flow variability, especially extreme events such as droughts and floods, is important in defining the magnitude, duration, and recurrence probability of many river-quality problems. Fortunately, most large rivers in the United States have fairly longterm, continuous-flow records that can be used to analyze both natural and regulated variabilities. Computer packages for statistical analysis of flow data are in common use by the Geological Survey and other agencies.

Water-temperature patterns are a major control of river quality because of their influence on biological activity. Patterns vary seasonally and in many basins correlate directly with air temperature. However, anomalous patterns can result from manmade influences such as impoundments and thermal discharges.

Many river-quality problems are manifested during high-temperature, high-insolation periods when biological activity is at a maximum. Water temperature records are available for many basins and can be analyzed to determine the optimum period for collecting data on biologically controlled problems such as DO depletion by carbonaceous wastes, nitrification, and excessive algal growth. In basins without sufficient records, seasonal water-temperature variations can be closely estimated from analysis of air-temperature data (Velz, 1970; Collings, 1973). Moreover, where the problem warrants, it is possible to compute equilibrium water temperature from data on air temperature, relative humidity, wind velocity, and solar radiation (Velz, 1970).

Three aspects of channel morphology-bed slope, cross-sectional geometry, and the nature of 
bed materials--are especially pertinent to riverxuality behavior. Bed slope, together with flow volume, defines the rate of energy dissipation along the course of a river. Bed slope thus partly governs mixing phenomena, transport of materials, time of travel, and processes such as reaeration.

Width and depth are the primary characteristics of cross-sectional geometry. These characteristics partly control the same important processes as bed slope. Moreover, in conjunction with the nature of bed materials, width and depth control the surface-to-volume ratio of river reaches, and thus define the availability of surfaces for biological growth. Information on cross-sectional geometry of most large rivers is available from the U.S. Army Corps of Engineers, the National Oceanic and Atmospheric Administration, the Geological Survey, or local agencies responsible for controlling river navigation. Where adequate data are lacking, inexpensive echo-sounding equipment can be used to characterize the geometry in a relatively short time. Width and depth characteristics vary with discharge and must be adjusted to each flow regime.

The nature of bed materials determines to a large extent the types of biological communities that inhabit different river reaches. For example, different groups of organisms thrive in mud, sand, and gravel. Bed-material characteristics are primarily determined by geology, topography, and man's activities. General information on the bed materials is available for many rivers from reports of State agencies, intrastate river-basin commissions, the Army Corps of Engineers, and the Geological Survey.

An example of the types of pertinent physical information commonly available for United States rivers is illustrated in figure 2 and table 1 . These data were available from existing records and reports on the Willamette River. The data were compiled into their presented form as a basis for selecting sampling reaches and stations for assessment of DO depletion and potential algal problems.

\section{SELECTION OF ASSESSMENT METHODS}

River quality encompasses all the processes on land, in air, and water, and the actions of society that affect the health of rivers. With this broad perspective, a wide spectrum of interpretive methods is needed to conduct comprehensive assessments.

Four types of methods are being used in the Willamette study:

1. Information matrices for planning the study (see Rickert and others, 1973), and for relating assessment results to planning alternatives.

2. Mathematical models for assessing problem variables that can be quantitatively modeled.

3. Interpretive maps for relating land-use activity to environmental impacts.

4. Descriptive methods for assessing problems that presently cannot be modeled, mapped, or addressed through matrices.

The predictive capability of these methods ranges from qualitative to quantitative. Quantitative assessments imply a sound numerical prediction of a future condition and are obtained through mathematical modeling. For example, a wellverified DO model (method 2 ) is being used to predict future DO concentrations of the Willamette River at selected sites under specified conditions of pollutional loading, temperature, and flow.

Qualitative assessments imply a general knowledge of the manner in which environmental and cultural factors inay combine to affect future conditions. Numerical predictions are not made. For example, a qualitative descriptive assess-

TABLE 1.-Selected physical characteristics of the main stem Willamette River, Oreg.

[Characteristics refer to summer low-flow conditions of $6 \times 10^{3} \mathrm{ft}^{3} / \mathrm{s}$ at Salem]

\begin{tabular}{|c|c|c|c|c|c|c|}
\hline Reach & $\underset{\text { (mi) }}{\text { Length }}$ & $\begin{array}{l}\text { Approximate } \\
\text { bed slope } \\
\text { (ft } / \mathrm{mi} \text { ) }\end{array}$ & Bed material & $\begin{array}{c}\text { Representative } \\
\text { midchannel } \\
\text { water depth } \\
\text { (ft) }\end{array}$ & $\begin{array}{l}\text { Velocity } \\
\text { (mi/hri }\end{array}$ & $\begin{array}{c}\text { Approximate } \\
\text { traveltime } \\
\text { in reach } \\
\text { (hrs) }\end{array}$ \\
\hline $\begin{array}{l}\text { Tidal } \\
\text { Reach (1) }\end{array}$ & 26.5 & $<0.1$ & $\begin{array}{l}\text { Intermixed clay, sand, } \\
\text { and gravel. }\end{array}$ & 40 & ${ }^{1} 0.11$ & 240 \\
\hline $\begin{array}{l}\text { Newberg } \\
\text { Pool (2) }\end{array}$ & 25.5 & .12 & $\begin{array}{l}\text { Intermixed clay, sand, and } \\
\text { gravel with some cobbles. }\end{array}$ & 25 & 1.27 & 94 \\
\hline Upstream & & & & & & \\
\hline Reach (3) & 135 & 2.8 & Mostly cobbles and gravel. & 7 & 22.0 & 68 \\
\hline
\end{tabular}

${ }^{1}$ Calculated by volume displacement method using channel cross-sectional data

2Calculated from dye study conducted by U.S. Geologieal Survey (Harris, 1968) 

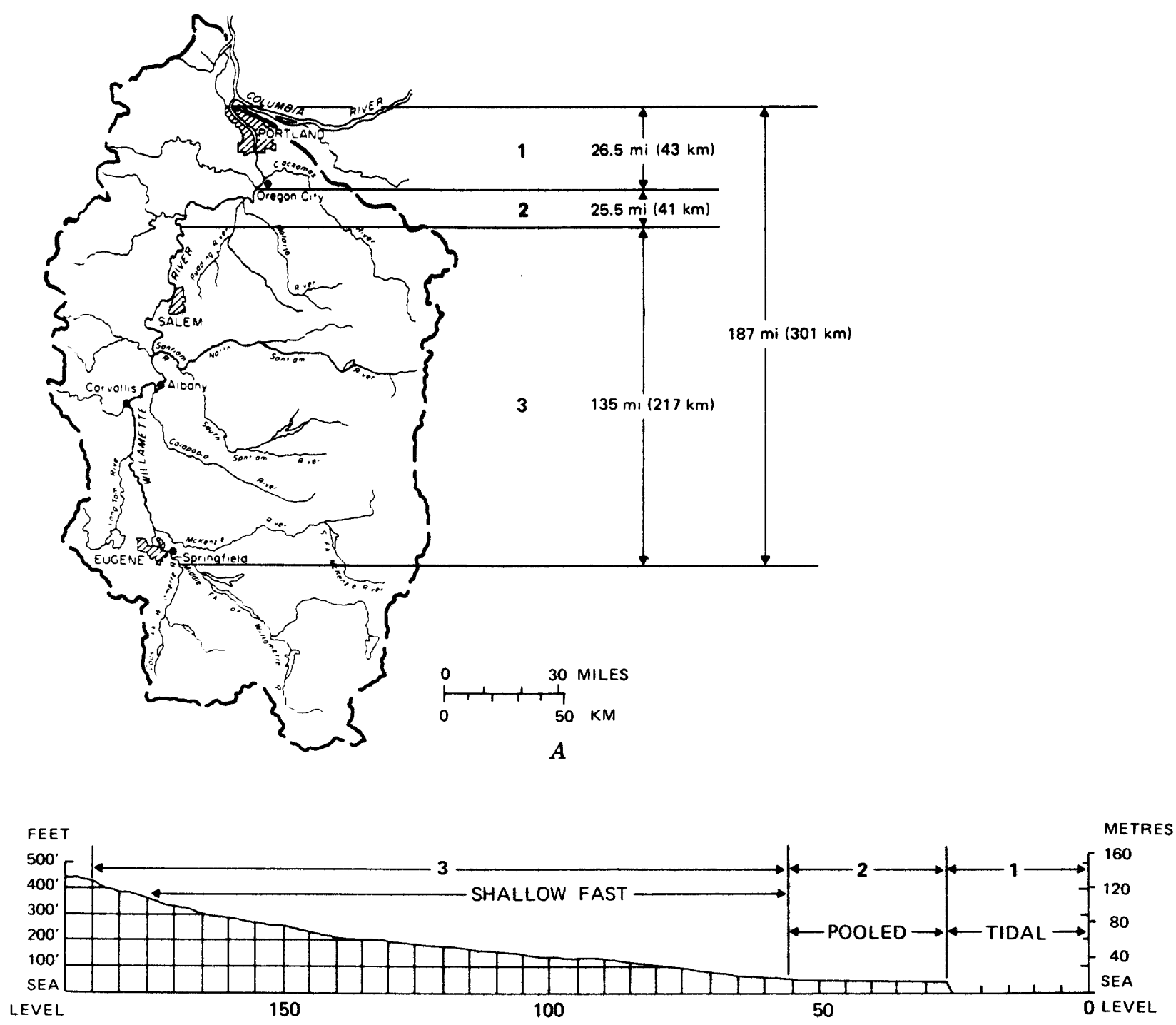

DISTANCE, IN RIVER MILES ABOVE MOUTH

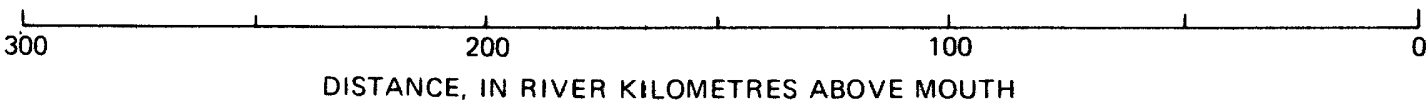

$B$

FIGURE 2.-Diagram representing the Willamette River, Oreg. $A$, Distinctive hydrologic reaches. $B$, Elevation profile.

ment (method 4 ) is being made of the Willamette River to determine whether algal problems are likely to develop from increases in algal-nutrient concentrations, changes in river hydrology (flow, mixing, temperature), neither, or both.

Semiquantitative assessments combine various elements of the quantitative and the qualitative. For example, a combination of interpretive maps and information matrices (methods 1 and 3 ) is being used for the Willamette River basin to relate terrain, land-use activity, and erosional-depositional features. The matrices qualitatively summarize an array of quantitative data to provide estimates of the relative severity of erosionaldepositional impacts associated with different activities in different parts of the basin.

The objective of assessment is to provide information that is sound, appropriate, and adequate for planning needs. The ideal would be to possess the scientific capability to quantify through 
mathematical modeling all processes and variables that give rise to river-quality problems. At present, however, many complex processes such as those appearing in the mid and upper parts of the triangle in figure 3 are difficult, if not impossible, to model in a practical, applied sense. (See Hines and others, 1975; Rickert and Hines, 1975.) This stems primarily from the fact that appropriate assumptions and accurate model parameters are difficult to develop because knowledge of these processes is presently very limited. Moreover, this poor state of knowledge makes it difficult to design data programs for elucidating the processes at reasonable cost.

Thus, at present, mathematical modeling is not realistically applicable to practical assessment of all river-quality problems. Comprehensive studies require several methods and, often, the most appropriate for a specific problem will be qualitative. Generally, the less quantitative the method, the less predictive are the results. Nevertheless, qualitative assessments are very valuable to decisionmakers, often providing critical information that cannot be obtained by other methods. The primary task of the scientist, then, is to select a method that fits the context of the problem, the basin complexity, the desired degree of detail, and the urgency with which the results are needed.

For complex, poorly understood problems, the scientist would best serve the planner by selecting a qualitative method for a timely preliminary assessment. The scientist can then provide a careful delineation of needs for conducting further work to upgrade assessments to more quantitative levels. Through this approach, the planner will have some information quickly, will know the limitations he must exercise in its use, and can suggest rational interim solutions while awaiting subsequent assessments.

Qualitative methods are often the most reasonable approach for assessing the impacts of land-use activity on land and river quality. For example, in the case of erosion problems related to land development, there is excellent general understanding of the basic processes and the kinds of data required to conduct in-depth assessments. Thus, a quantitative modeling approach might seem possible. However, the usual drawback to such a quantitative approach is an inability to obtain data in sufficient detail. Faced with analyzing the erosion potential of a large drainage basin, the resource scientist will usually be unable to find or

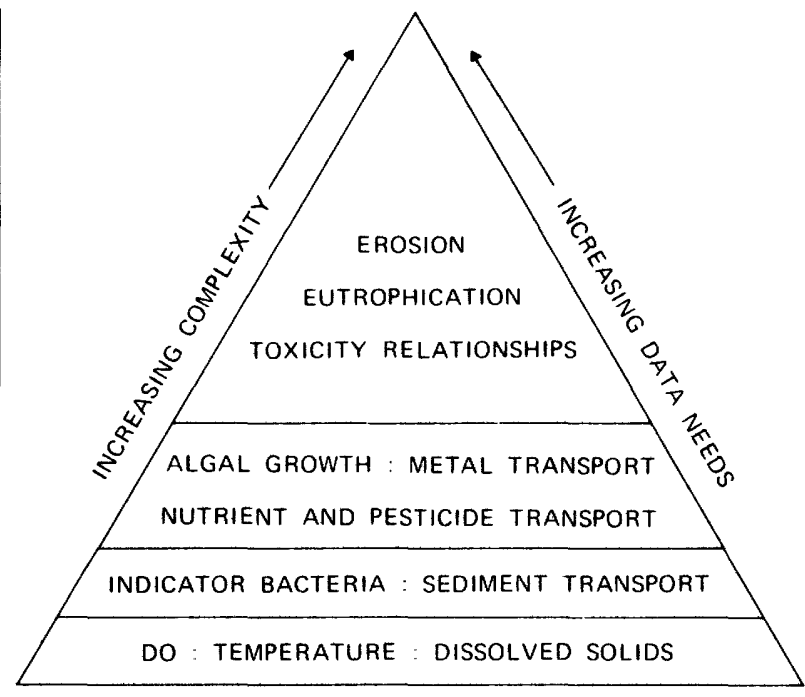

Figure 3.-Diagram showing relative difficulty of applied modeling.

collect enough data in a reasonable time to allow use of a quantitative method. Given the current availability of data, the most appropriate approach will usually be a qualitative method that interrelates land-use activity, erosion potential, and potential impacts on river quality.

An important consideration in selection of methods is that limitations on the use of results must be carefully explained. For example, in mapping assessments, limitations are often inherent in, and sometimes obscured by, the scale at which information is presented. A qualitative mapping assessment (or any qualitative result), if misapplied or overapplied, can create havoc in the resource-management process. The resource scientist needs to accept the challenge that expert explanation of the limitations of a qualitative assessment is equal in importance to the assessment itself.

In theory, sound quantitative assessments are more definitive than qualitative assessments. The fact is, however, that most river-quality processes are so complex the scientist is never entirely sure of the reliability of supposedly quantitative results. For example, in formulating a DO model, the scientist can collect statistically reliable data on biochemical oxygen demand (BOD), DO, and flow. However, if photosynthesis or benthic demands affect the DO regime, the scientist may be unable to define these effects in statistically reliable terms. Thus, even with sound assessments using "quantitative" methods, the scientist must take 
care to explain the uses and limitations of results.

The resource scientist should be constantly aware that all usable assessment methods, no matter how qualitative or quantitative, are based upon the scientific principles. Given today's emphasis on modeling, computers, and equipment, this is critical to remember; otherwise, assessment studies can easily become "method oriented" rather than "problem oriented" (Platt, 1964).

\section{IDENTIFICATION, COLLECTION, AND COLLATION OF REQUIRED DATA}

Valid data are the basis of sound resource assessment. The kinds and amounts of data required to assess a river-quality problem depend primarily on the complexity of the river process, the size of the study area, and the method chosen for assessment.

Qualitative methods of assessment generally require less data than do quantitative methods, and also may permit greater utilization of existing data. For example, experienced investigators have developed qualitative maps of erosion potential from existing data on climate, slope, geology-soils, runoff, and erosional-feature locations (Brown and Jackson, 1973, 1975).

Likewise, a qualitative reach-to-reach analysis of DO variations can often be made from existing data collected by State and Federal agencies for water-quality monitoring and pollution-control surveillance. In contrast, data collected for such purposes are usually poorly suited for calibration and verification of an applied DO model. This lack of suitability stems from several factors (Hines and others, 1975):

1. Correlative data on hydrology and especially waste discharges are seldom determined. As a result, most monitoring and surveillance data indicate effects rather than give insight into causes. A river-quality model can be structure imitating and predictive only if cause-effect relationships are quantitatively established.

2. Monitoring programs usually collect limited grab samples at widely dispersed sites under a variety of conditions. Such data rarely provide quantitative knowledge of reachto-reach, cross-sectional, and daily variations. This is particularly true for a nonconservative, dynamic variable such as DO.

3. The relation between riverflow and time of travel is seldom known or is overlooked in the planning of monitoring programs. Therefore, results obtained from individual sites represent a synoptic picture of the river only if samples are collected during a long-term, steady-state flow condition and at the same time of day. This is rarely the case.

4. The inherent sampling and analysis errors for river-quality variables are relatively large. Consequently, to develp an applied riverquality model, a number of sample sets are necessary to define a range of error as an index of inherent variability.

The tendency today is to conduct river-quality assessments solely on the basis of existing data. This approach is mostly ineffective, because existing data are seldom adequate to support intensive assessment of multiple problems. In fact, existing data are deemed insufficient even to determine whether the Nation's water quality is generally getting better or worse (McKelvey, 1974).

Standard water-quality monitoring networks will never provide all the data needed to conduct intensive river-quality assessments. It is unfeasible to design a network to include enough parameters at enough sites at suitable sampling frequencies so that all potential problems can be adequately assessed. Even if such a network were theoretically possible, the cost would be prohibitive. Thus, each new study will be faced with collecting information to fit specific needs not covered by existing data. Collection of good data requires money, but the cost should be weighed against the possible cost of poor planning decisions that might result from inadequate assessments or arbitrary conclusions. The pertinent question is not what the data will cost, but what an unsound planning decision will do to river quality and eventually cost the taxpayer.

To obtain appropriate data to assess specified problems, a four-step approach is being used in the Willamette study:

1. Identify the types of data required to assess each problem.

2. Collate and analyze pertinent existing data. Where these data appear insufficient to assess the problem adequately, proceed to step 3.

3. Design a reconnaissance study to determine: a. The major factors that actually affect the river-quality problem in question. 
b. The anticipated range of values for each factor.

c. The amount of data needed to analyze each cause-effect relationship.

4. On the basis of steps 1 through 3 , design and conduct a field and laboratory datacollection program at an intensity appropriate to adequately assess the problem.

In the Willamette study, certain problems are being assessed entirely through the use of existing data (step 2). For example, existing streamflow records have provided a sound basis for the mathematical modeling of reservoir releases and the flow aspects of DO depletion. In addition, existing data are sufficient for qualitative analysis of climate, slope, geology, and soils as a basis for mapping basinwide erosion potential.

Step 2 (collation and analysis of existing data) plays a vital role in data programs, even for those cases in which new data must be collected. For example, existing data were analyzed for study of DO depletion in the Willamette River. Although the records were not suitable for providing a reliable analysis of cause-effect relationships, the data did indicate (1) the general magnitude of DO depletion (up to 40 percent depletion of DO saturation), (2) the affected reaches of the river (the lower 80 miles, $129 \mathrm{~km}$ ), (3) the yearly period of most severe DO depletion (July-August), and (4) the fact that summer flow was effectively steady state and greatly augmented by reservoir releases. This information provided the background for a reconnaissance-level study.

The reconnaissance-level study (step 3) was made to determine (1) river mixing and flow patterns, (2) waste-loading characteristics, (3) the presence or absence of benthic oxygen-demanding deposits, and (4) expected ranges of model parameter values. Results of the survey indicated that several major changes had occurred since 1951 and 1960 when Velz $(1951,1961)$ studied the DO regime of the Willamette: BOD loadings were much lower and more uniform because of basin-wide secondary treatment; river deoxygenation rates were much lower; large benthic deposits were absent except in Portland Harbor; and detention time and river-channel geometry, and thus reaeration rates, had been affected by dredging. One important condition remained unchanged: the river was still well mixed in most reaches.

Such findings indicated that a simpler model configuration could be used than was originally anticipated. The results also provided the basis for design and implementation of an efficient datacollection program for model calibration and verification (Rickert and Hines, 1975).

Collection of valid data requires time in addition to money. The time element is of prime importance in all types of river-quality assessments, but especially for quantitative methods such as mathematical modeling. An inverse relationship exists between the complexity of a river-quality process and the ability to produce sound modeling assessments within a given timespan. For many rivers, where sufficient and valid hydrologic data are available, practical, reliable flow models can be calibrated and verified within a year. Possible exceptions would include extremely large basins, small rivers having no past streamflow records, complex estuarine systems, and basins experiencing prolonged periods of marked extremes such as drought.

In sharp contrast, data for few if any rivers are adequate to permit formulation of an applied DO model. In cases where only a specific period of the year needs to be modeled, sufficient data may be collected in 1 year to calibrate and verify a model. In systems that are hydraulically complex, or where assessments are needed over large variations of flow, 2 to 3 years of data collection may be needed to produce a reliable DO model.

For highly variable parameters such as indicator bacteria, considerably more time and larger amounts of data may be required to produce a reliable and practical model.

Even farther up on the data-requirement scale (fig. 3) is the process of eutrophication. Certain critical subprocesses such as nutrient transport and algal-growth dynamics are so poorly understood that programs for collecting definitive data are difficult to design. In fact, the great difficulty of collecting sound data on sinks and sources of nutrients and on environmental controllers of algal growth makes it questionable whether eutrophication can presently be modeled in a practical applied sense (McGauhey, 1974). Several attempts have been made at modeling eutrophication, and perhaps the best practical study to date (Jaworski and others, 1971) was based on more than 5 years of specialized data collection.

Somewhat equivalent to the difficulty of modeling eutrophication are the problems inherent in the mathematical modeling of sediment yield. Conceptually, the various subprocesses can be 
modeled. As explained by Bennett (1974), the present lack of practical models stems from the difficulty of collecting enough reliable data for calibration and verification. Many years of specialized data collection would be needed to produce a sound and practical sediment-yield model.

DATA ANALYSIS, METHOD FORMULATION, AND THE TESTING OF PREDICTIVE CAPABILITY

After collection of the initial data, the assessment proceeds with a step (fig. 4) that begins with (1) analysis of the data, (2) incorporation of analyzed data in the selected assessment method, and (3) testing of the data-method package to determine its predictive capability. If the predictive capability is less than adequate, as measured against predetermined criteria, the assessment method is reformulated or additional data are collected. The process then recycles. Once the datamethod package is deemed suitable for projecting impacts, it is ready for application to planning. This procedure, as noted in figure 1 (River quality assessment, step 5) and as outlined in figure 4, is referred to as data analysis, method formulation, and the testing of predictive capability.

This procedure can be illustrated by considering the process of mathematical modeling. First, an initial set of data is analyzed and interpreted. Next, the data are used to formulate and calibrate the model (incorporation of data and method). Following this, model outputs (predicted values) are compared to a second set of values; this is verification. If the fit is poor, new data must be collected to recalibrate the model or the model reformulated until outputs can adequately reproduce observed conditions. Only when the model is adequately verified is it ready for use in resource planning.

Development of other data-assessment method packages goes through the same procedure, regardless of whether the predictive capability is qualitative or quantitative. The important points of this procedure are first, that the data must be carefully analyzed prior to incorporation with the method, and second, that the data-method package must be tested, and, if necessary, adjusted before impact assessment can begin. There is a tendency in some resource assessments to skip or give short shrift to these two highly important points. Consideration of figure 4 should help to emphasize their essential role in the overall procedure.

\section{FORECASTING IMPACTS OF}

\section{PLANNING ALTERNATIVES}

The goal of river-quality assessment is to use predictive tools to provide decisionmakers with the best attainable insight to the impact of planning alternatives on delineated problems. Nearly all land and water development affects river quality, but the physical and cultural complexity of most river basins precludes assessment of each and every impact. An approach for dealing with this problem is to screen the full spectrum of planning proposals as to possible impacts on the most important problems.

This approach can narrow a myriad of possibilities to a workable program. Because most of the selection depends on judgment rather than hard fact, the process should be a joint venture between the resource scientist and planner. The scientist can provide information and knowledge on river quality and the possible impacts of water and land development. The planner can provide insight as to how, when, and where basin development will occur under anticipated social, economic, and political stimuli. The joint venture can assure that all proposals with large impact potential are included and proposals with little or no impact potential are excluded.

During selection of alternatives for assessment, the resource scientist and planner should resist the temptation to focus only on those forms that are presently "in vogue." For basin planning, the complete spectrum of alternatives stretches from zero growth to uncontrolled growth and development. For approaches to resource development and protection, the spectrum stretches from those having well-documented statutory regulations and funding mechanisms to innovative approaches for which the legal and funding aspects are not yet established.

Assessments might indicate that previously untried alternatives are reasonable from the standpoint of river quality. If so, the planners and decisionmakers can later determine the legal and financial advisability of each new alternative. Ideas, funding mechanisms, and laws can be changed when there is sound reason to do so.

River-quality assessment is a never-ending process, and even the most comprehensive studies are likely to become outdated. The resource scientist can respond to this problem in three ways: (1) 


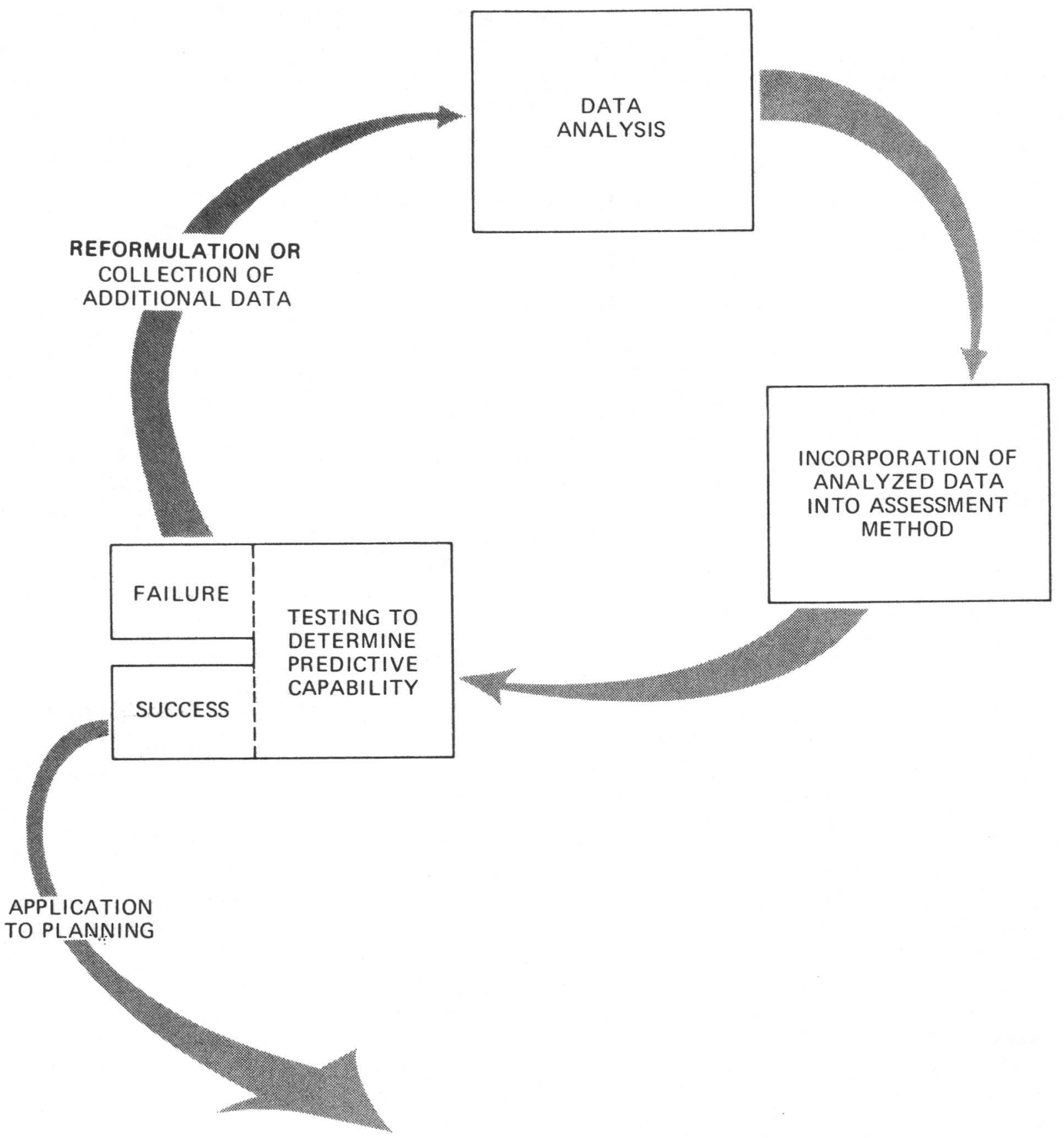

FIGURE 4.-Interrelation of data analysis, method formulation, and the testing of predictive capability.

frequently assess newly developed alternatives through use of existing methods; (2) develop programs to improve the data and knowledge base for future assessments; and (3) periodically, perhaps every 5 to 10 years, conduct a full-scale reassessment that incorporates new scientific data, new planning information, and new assessment technology. The three-element process is impor- tant, because badly outdated assessments might be more detrimental to decisionmaking than complete lack of environmental knowledge.

\section{COMMUNICATION OF RESULTS}

The resource scientist should carefully design reports so results can be easily and quickly understood. Reports need to be written in nontechnical 


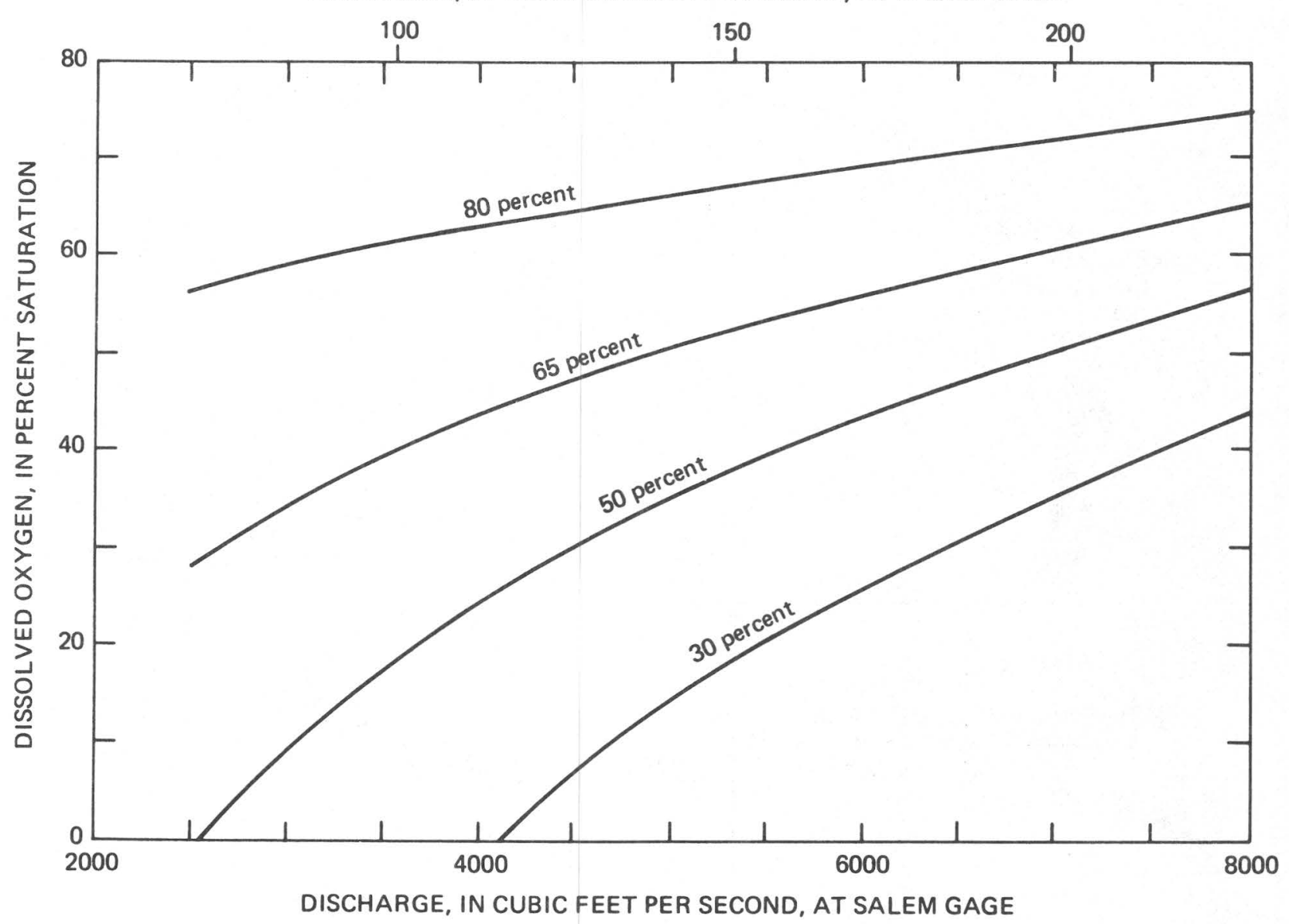

FIGURE 5.-Relation between dissolved oxygen and summer-condition discharge for Willamette River at river mile 6.

language and style, with emphasis on graphical reporting of results.

Techniques for graphically expressing results vary with the nature of the problem and the method of assessment. For modeling assessments, a useful technique for presenting results is the control-curve concept described by Velz (1970). For example, figure 5 illustrates predicted relationships between percentage DO saturation and discharge at various reductions of average (in 1950) BOD loading. Each curve was computed from Velz's (1951) DO model. The curves are useroriented and permit assessment of three factors on one graph. Such curves provide assessment flexibility and enable the user to simultaneously evaluate numerous planning and management alternatives.

Two approaches for presenting integrated earth resource-water resource assessments are mul- tiple-factor maps and information matrices. Steps 1 and 2 of figure 6 portray the development of an erosional province map for the Willamette River basin. The inputs to the map are an up-to-date photomosaic base; high-altitude, false-color, infrared photography; and composite overlays of selected earth- and water-resource factors. The components are integrated to provide a product that relates natural terrain properties and landuse activity to the type, number, and extent of erosional features.

Step 3 of figure 6 illustrates a matrix for converting information from the erosional province map into a format useful to resource planners. The matrix lists erosional provinces as columns and land-use activities as rows. The erosional provinces are numerically ranked in order of their potential to erode, whereas the land-use activities are ranked in their order of land-surface disrup- 
BASIN

РноTO-

MOSAIC

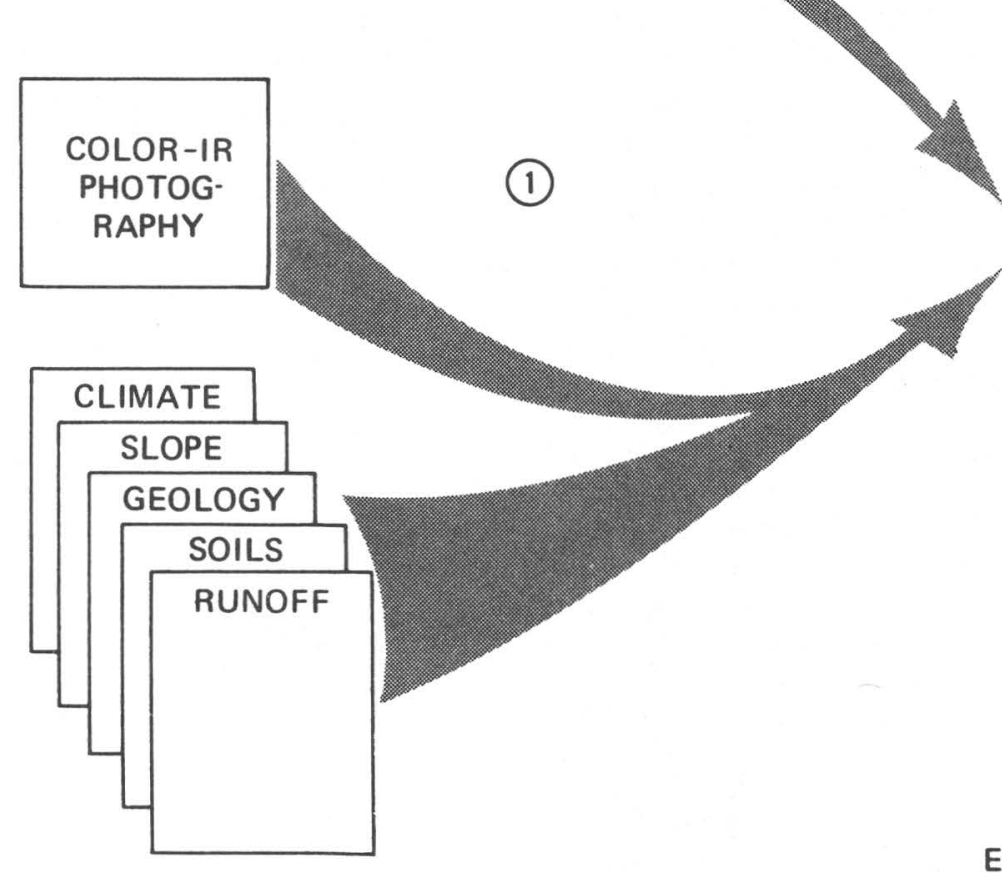

(2)

EROSIONAL

PROVINCE

MAP

EROSIONAL PROVINCES

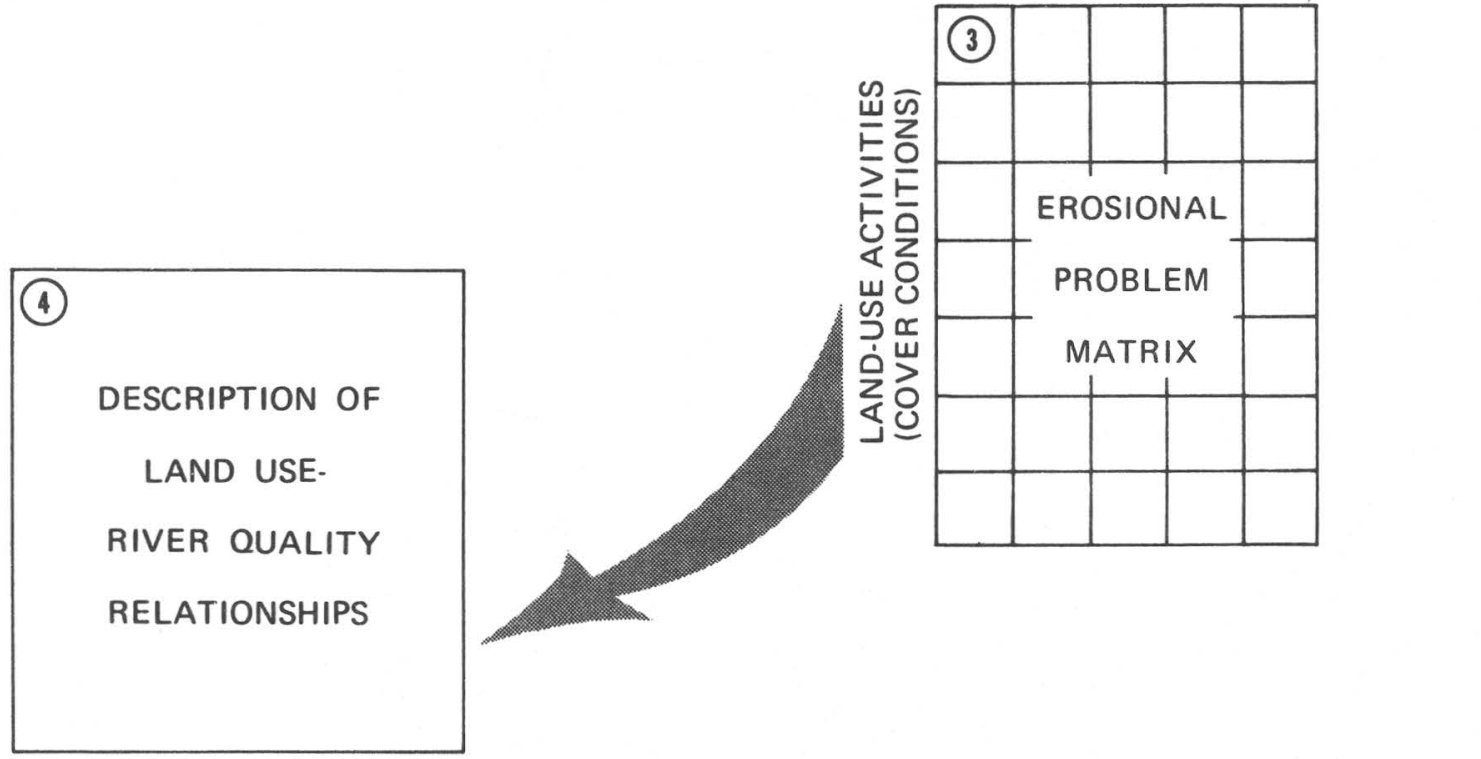

FIGURE 6.-Process of assessing the impacts of land-use activity on erosion and river quality. 
tion. The matrix body records the product of the ranks from each column and row. The magnitudes of these products indicate the relative seriousness of erosional problems likely to develp under the various combinations of erosional provinces and land-use activities.

\section{PROGRAM EVALUATION}

All scientific programs need to be evaluated to determine strengths and weaknesses and to develop criteria for the future. In river-quality assessment, program evaluation provides the framework for improvement of methods and knowledge. The evaluation, like the assessment itself, should be a joint effort between scientists and planners. Each party needs to evaluate the overall program, but responsibility for duties can be divided. For example, all parties should consider the following:

1. Were they able to communicate freely and effectively with each other? If not, how can the communication process be improved?

2. What river-quality problems, if any, need further attention to upgrade the working knowledge?

3. How often should a detailed comprehensive assessment be made of river quality?

The resource scientist should address the following questions:

1. Was the existing data base adequate for conducting the assessment? If not, what improvements could be made in Federal, State, and local programs to provide the data required for future assessments?

2. Were the assessment methods adequate for the task? What kinds of new methods should be developed for future use?

The planners, first alone and then with the resource scientist, should consider these questions:

1. Do the assessments provide the right kind of information? If not, what improvements could be made?

2. Were results reported in an easily understandable, easy-to-use form? If not, how could understandability and utility be improved?

These questions are only a framework of the kinds of questions that need to be evaluated, discussed, and rediscussed to provide a basis for future efforts. To paraphrase Bella and Overton (1972), the quality of the questions we ask now, and seek answers to, will determine the quality of tomorrow's available information.

\section{SUMMARY AND DISCUSSION}

Nearly all forms of growth and development exert some impact on river quality. Thus, to achieve desirable river quality at acceptable cost, it is imperative that planning decisions be based on sound impact assessments rather than on arbitrary assumptions.

Comprehensive resource assessments require a rational framework for proceeding with scientific analysis. The Willamette study was undertaken to define such a framework and, also, to develop practical methods and to determine the data requirements for assessing several of the Nation's most prominent river-quality problems.

The procedural framework described in this circular provides only a starting point for assessment of river quality. Rivers and their basins are dynamic, and the processes and problems within them result from the interaction of complex natural variables with man's activities and alterations. The dominant problems are usually so complex that desk-top analyses have little likelihood of success. Moreover, each river is an entity unto itself and must be studied as such. A resource scientist must visit and examine a river basin in detail to adequately understand the environmental conditions, the problems, and the data needs.

Each new assessment will require modifications of existing methods, and, in some cases, development of new methods. Each intensive study will also require the collection of new data. In addition to the technical factors, the resource scientist needs to build a relationship of mutual understanding with the basin planners and decisionmakers.

The resource scientist must ask and answer many questions to conduct a successful riverquality assessment. Perhaps the three most important questions need to be asked at the beginning of each study:

1. Have the relevant problems been delineated?

2. What types of data programs are needed to provide a technically sound assessment?

3. How much time is needed to provide information that is adequate for decisionmaking?

The ultimate success of a resource assessment is largely determined by its initial formulation. Careful answers to these questions, together with thoroughly defined objectives, will provide a sound start to each new assessment. 


\section{REFERENCES CITED}

Bella, D. A., and Overton, W.S., 1972, Environmental planning and ecological possibilities: Am. Soc. of Civil Engineers, Jour. Sanitary Eng. Div., v. 98, no. SA3, Proc. Paper 8994, p. 579-592.

Bennett, J. P., 1974, Concepts of mathematical modeling of sediment yield: Water Resources Research, v. 10, no. 3, p. 485-492.

Brown, W. M., III, and Jackson, L. E., Jr., 1973, Preliminary map of erosional and depositional provinces and descriptions of sediment-transport processes in the south and central San Francisco Bay region, California: U.S. Geol. Survey Misc. Field Studies Map MF-515.

1975, Sediment source and deposition sites and erosional and depositional provinces, Marin and Sonoma Counties, California: U.S. Geol. Survey Misc. Field Studies Map MF-625.

Collings, M. R., 1973, Generalization of stream-temperature data in Washington: U.S. Geol. Survey Water-Supply Paper 2029-B, 45 p.

Executive Office of the President, 1964, Coordination of Federal activities in the acquisition of certain water data: Bur. of the Budget Circ. A-67.

Gleeson, G. W., 1972, The return of a river, the Willamette River, Oregon: Advisory Comm. on Environmental Sci. and Technology and Water Resources Inst., Oregon State Univ., Corvallis, 103 p.

Harris, D. D., 1968, Travel rates of water for selected streams in the Willamette River basin, Oregon: U.S. Geol. Survey Hydrol. Inv. Atlas HA-273.

Hines, W. G., Rickert, D. A., McKenzie, S. W., and Bennett, J. P., 1975, Formulation and use of practical models for river-quality assessment: U.S. Geol. Survey Circ. 715-B, p. B1-B13.

Howells, D. H., 1971, Land use function in water quality management: Water Resources Bull., v. 7, no. 4, p. 162-170.
Jaworski, N. T., Lear, D. W., Jr., and Villa, Orterio, Jr., 1971, Nutrient management in the Potomac estuary: Environmental Protection Agency, Water Quality Office, Tech. Rept. 45, 61 p.

McGauhey, P. H., 1974, Synopsis of workshop on modeling the eutrophication process, in Middlebrooks, E. J., Falkenborg, D. H., and Maloney, T. E., eds., Modeling the eutrophication process: Ann Arbor Sci., 228 p.

McKelvey, V. E., 1974, Water quality-is it getting better or worse?: Paper presented before the Seventh Internat. Water Quality Symposium, Washington, D.C., April 23, 1974.

Oregon Department of Environmental Quality, 1970, Water quality control in Oregon: Oregon Dept. Environmental Quality, 28 p.

Platt, J. R., 1964, Strong inference: Science, v. 146, no. 3642 , p. 347-353.

Rickert, D. A., and Hines. W. G., 1975, Methods and data requirements for river-quality assessment: Water Resources Bull. (in press).

Rickert, D. A., Schneider, W. J., and Spieker, A. M., 1973, A procedure for assessing water resources for urban planning: Water Resources Bull., v. 9, no. 4, p. 768-792.

Velz, C. J., 1951, Report on natural purification capacities, Willamette River: Natl. Council for Stream Improvement of the Pulp, Paper, and Paperboard Industries, Inc., School of Public Health, Michigan Univ., Ann Arbor, 80 p.

1961, Supplementary report on lower Willamette River waste assimilation capacity: Natl. Council for Stream Improvement of Pulp, Paper, and Paperboard Industries, Inc., School of Public Health, Michigan Univ., Ann Arbor, 28 p. 1970, Applied stream sanitation: New York, John Wiley and Sons, Inc., 619 p.

Willamette Basin Task Force, 1969, Main report, Willamette Basin Comprehensive Study: Pacific Northwest River Basins Comm. Rept., 155 p.

Wolman, M. G., 1971, The nation's rivers: Science, v. 174, no. 4112, p. 905-918. 
